\title{
Postmortem pulmonary CT in hypothermia
}

Schweitzer, Wolf ; Thali, Michael J ; Giugni, Giannina ; Winklhofer, Sebastian

DOI: https://doi.org/10.1007/s12024-014-9611-2

Posted at the Zurich Open Repository and Archive, University of Zurich ZORA URL: https://doi.org/10.5167/uzh-100578

Journal Article

Published Version

Originally published at:

Schweitzer, Wolf; Thali, Michael J; Giugni, Giannina; Winklhofer, Sebastian (2014). Postmortem pulmonary CT in hypothermia. Forensic Science, Medicine, and Pathology, 10(4):557-569.

DOI: https://doi.org/10.1007/s12024-014-9611-2 


\title{
Postmortem pulmonary CT in hypothermia
}

\author{
Wolf Schweitzer • Michael Thali • Giannina Giugni • \\ Sebastian Winklhofer
}

Accepted: 4 September 2014/ Published online: 19 October 2014

(C) Springer Science+Business Media New York 2014

\begin{abstract}
Fatal hypothermia has been associated with pulmonary edema. With postmortem full body computed tomography scanning (PMCT), the lungs can also be examined for CT attenuation. In fatal hypothermia cases low CT attenuation appeared to prevail in the lungs. We compared 14 cases of fatal hypothermia with an age-sex matched control group. Additionally, 4 cases of carbon monoxide $(\mathrm{CO})$ poisoning were examined. Furthermore, 10 test cases were examined to test predictability based on PMCT. Two readers measured CT attenuation on four different axial slices across the lungs (blinded to case group and other reader's results). Hypothermia was associated with statistically significantly lower lung PMCT attenuation and lower lung weights than controls, and there was a dose-effect relationship at an environmental temperature cutoff of $2{ }^{\circ} \mathrm{C}$. CO poisoning yielded low pulmonary attenuation but higher lung weights. General model based prediction yielded a $94 \%$ probability for fatal hypothermia deaths and a $21 \%$ probability for non-hypothermia deaths in the test group. Increased breathing rate is known to accompany both $\mathrm{CO}$ poisoning and hypothermia, so this could partly explain the low PMCT lung attenuation due to an oxygen dissociation curve left shift. A more marked distension in fatal hypothermia, compared to $\mathrm{CO}$ poisoning, indicates that further, possibly different mechanisms, are involved in these cases. Increased dead space and
\end{abstract}

W. Schweitzer $(\bowtie) \cdot$ M. Thali · G. Giugni

Institute of Forensic Medicine, University of Zürich,

Winterthurerstr. 190, 8057 Zurich, Switzerland

e-mail: swisswuff@gmail.com

S. Winklhofer

Department of Diagnostic and Interventional Radiology, University Hospital Zurich, Raemistrasse 100, 8091 Zurich, Switzerland increased stiffness to deflation (but not inflation) appear to be effects of inhaling cold air (but not $\mathrm{CO}$ ) that may explain the difference in low PMCT attenuation seen in hypothermia cases.

Keywords Computed tomography · Hypothermia . Postmortem $\cdot$ Pulmonary emphysema

\section{Introduction}

The diagnosis of fatal hypothermia is based on a number of hypothermia-associated observations as well as on exclusion $[1,2]$. On external inspection, the bright red discoloration of livor mortis, red to purple, or pink to brownishpink discoloration over the skin of extensor surfaces such as around the elbows or knees, as well as circumstantial indicators such as low environmental temperature or paradoxical undressing may indicate fatal hypothermia. At autopsy, bright red blood, Wischnewski erosions of the gastric mucosa [3], hemorrhage in the psoas muscle and acute pancreatic necrosis are typical $[4,5]$ but not specific [6] findings. Chemical test results that support the assumption of a prolonged agonal phase in fatal hypothermia include ketonuria [7].

Postmortem full body computed tomography (PMCT) is currently being included in a number of recent postmortem examination guidelines and standards $[8,9]$. We routinely perform PMCT scans of bodies admitted to our institute to supplement the autopsy examination. When viewing consecutive full body PMCT scans, we observed that fatal hypothermia, along with a number of other conditions, seemed to be associated with a considerably lower PMCT attenuation of the lungs, when compared to natural causes of death. 

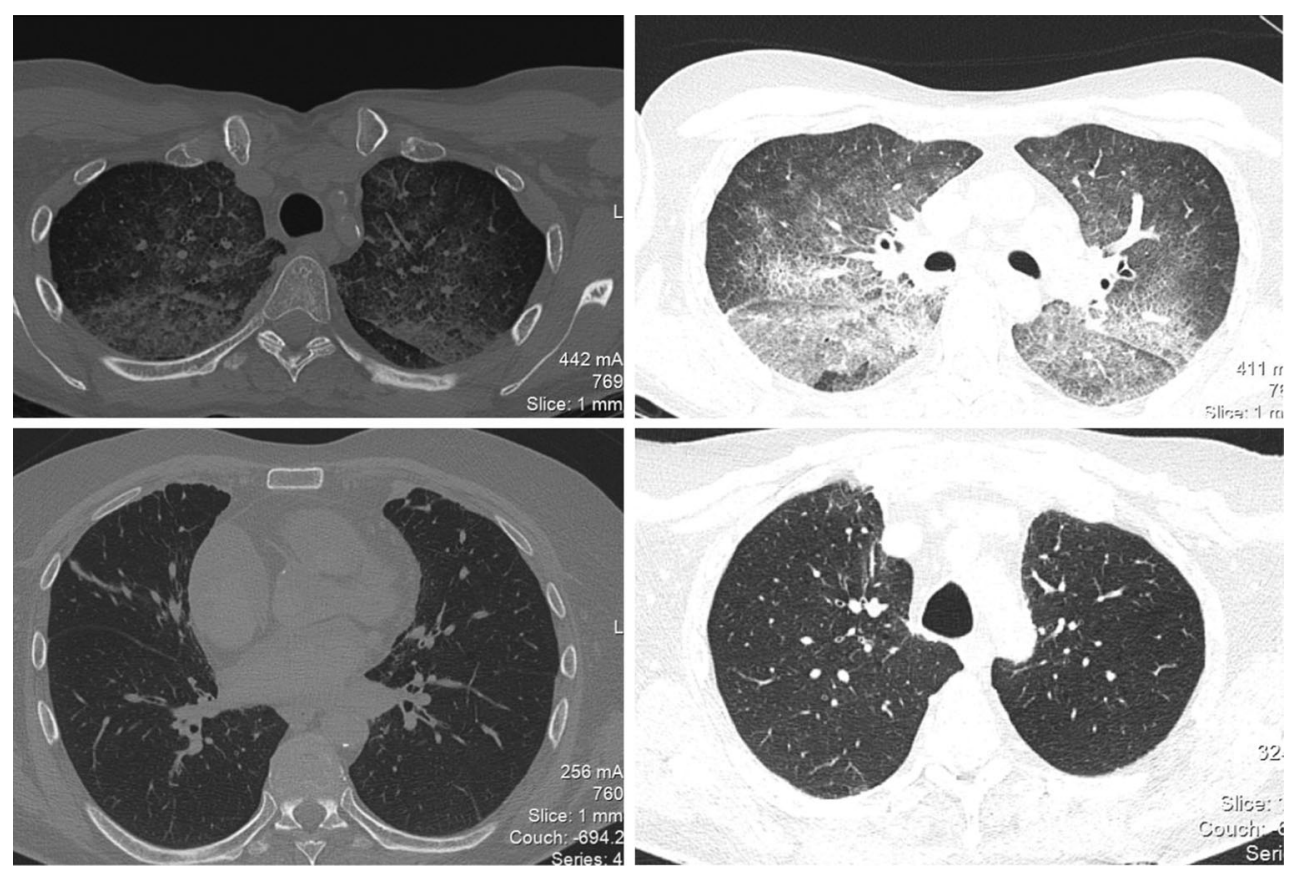

Fig. 1 A low PMCT attenuation in the lungs of hypothermic deaths (bottom row) compared to natural deaths (top row) appeared to be present in fatal hypothermia (but not only there). Top row Natural death without signs of hypothermia. Bottom row Death as consequence of hypothermia. Left column PMCT image shown using

Low PMCT lung attenuation typically signifies emphysema. Acute emphysema may be seen in cases of suffocation [10]. With increased breathing rate or obstruction of breathing, conditions such as carbon monoxide $(\mathrm{CO})$ poisoning or strangulation are expected to correlate with acute agonal pulmonary distension. There was a strong contrast between fatal hypothermia and controls on routine PMCT (see Fig. 1). This was not expected, as forensic pathology texts list pulmonary edema $[4,5]$ or even bronchopneumonia [11] as typical lung findings in such deaths. Conversely, classical forensic pathology books give no indication of there being any correlate for uniformly low PMCT lung attenuation such as acute emphysema, acute distension, or increased agonal hyperventilation in fatal hypothermia.

The aim of this study was to examine PMCT and autopsy correlates of acute distension, acute emphysema, and pulmonary edema in cases of fatal hypothermia in comparison with controls and in comparison with carbon monoxide poisoning, and to discuss possible explanations for the results.

\section{Materials and methods}

We performed a retrospective case-matched study of fatal hypothermia cases (group $\mathrm{H}$ ) and an age-sex matched

attenuation values that are windowed for bone viewing. Right column The PMCT images shown that are windowed for lung viewing. All images show axial PMCT images as they are routinely captured before autopsy

control (group C). Additionally, data was also compared with cases of carbon monoxide poisoning (group $\mathrm{CO}$ ), but since there were just four cases, no age-sex match was possible. Pulmonary PMCT attenuation, along with other findings, were compared. Lastly, a statistical model was determined. The model was then tested with the pulmonary PMCT attenuation of ten additional deaths (group T).

\section{Case review}

In our institute, full body PMCT imaging became routine for a number of indications in 2008, and for all bodies that were admitted to our institute in 2010. All cases that underwent both PMCT and subsequent autopsy at our institute were reviewed for data collection.

\section{Data collection}

Data collection involved the retrospective identification of data and protocols that were performed under the auspices of investigatory authorities for judicial investigations into suspicious or violent deaths. Selection criteria for the three groups $(\mathrm{H}, \mathrm{C}, \mathrm{CO})$ are detailed below. Data was collected in accordance with our institute's policies, local ethical committee's opinion, and laws pertaining to biomedical research. 
Data analysis

Autopsy data and circumstantial evidence were evaluated by one author of this study. Age, sex, temperature at the death scene, postmortem interval, and other details including the presence of pulmonary edema and lung weights were obtained from the autopsy reports. PMCT data was also evaluated for the presence of gas. PMCT attenuation was measured by two other authors as blinded readers.

\section{Hypothermia group $(\mathrm{H})$}

We were interested in pulmonary findings that resulted from direct influence of hypothermia before and during agony and death. Therefore, complications of initially survived hypothermia were not evaluated in this study.

Fourteen cases (5 women with a mean age of $55 \pm 21$ years and 9 men with a mean age of $54 \pm 22$ years) where (dry) hypothermia [4] was judged to be the main, or a contributing factor, to the cause of death were identified. There were no cases were findings of possible hypothermia were identified alongside drowning.

Further diagnostic considerations regarding fatal hypothermia are detailed below.

\section{Control group (C)}

The control group was age-sex matched to group H. Cases were selected randomly from the case review's respective age-sex-group (that was defined as age matching the age of the respective individual of group $\mathrm{H} \pm 2.5$ years and same sex).

Excluded mechanisms of death included drowning and gaseous and mechanical asphyxia such as strangulation and carbon monoxide poisoning. Advanced postmortem decomposition cases were also excluded because in these cases, morphological assessment of possible fatal hypothermia was too uncertain. Also, it was assumed that decomposition related gas could possibly confound any possible effects of hypothermia on the PMCT attenuation of lungs.

\section{Carbon monoxide poisoning group $(\mathrm{CO})$}

From the case review, all cases of fatal $\mathrm{CO}$ poisoning were included for this study in order to investigate the effect of suffocation on PMCT appearance of the lungs. The defining criteria for selecting these cases was whether carbon monoxide was judged to be the cause of death in the final report of the pathologist; carbon monoxide-hemoglobin values were relatively high (see Table 1).
Table 1 Group $\mathrm{H}$ (hypothermia) differs from the control group (C) in a number of details

\begin{tabular}{|c|c|c|c|}
\hline & Group $\mathrm{H}^{\mathrm{a}}$ & Group $\mathrm{C}^{\mathrm{a}}$ & Group CO \\
\hline Group size & 14 & 14 & 4 \\
\hline Age & $54.5 \pm 20.5 \mathrm{y}$ & $54.4 \pm 20.5 \mathrm{y}$ & $35.8 \pm 8.7 \mathrm{y}$ \\
\hline Sex & 5 female $/ 9$ male & 5 female $/ 9$ male & 2 female $/ 2$ male \\
\hline $\begin{array}{l}\text { Temperature at death } \\
\text { scene }\left({ }^{\circ} \mathrm{C}\right)\end{array}$ & $9.8 \pm 8.6^{\mathrm{b}}$ & $22.0 \pm 2.2^{\mathrm{b}}$ & $18.1 \pm 19.4$ \\
\hline $\begin{array}{l}\text { Postmortem interval } \\
\text { to } \mathrm{CT}\end{array}$ & $36 \pm 33$ & $32 \pm 24$ & $34 \pm 31$ \\
\hline $\begin{array}{l}\text { Acute intoxication } \\
\text { (alcohol and/or } \\
\text { drugs) }\end{array}$ & $7 / 14$ & $1 / 14$ & $1 / 4$ \\
\hline $\mathrm{CO}-\mathrm{Hb}(\%)$ & n.r. & n.r. & $73 \pm 10$ \\
\hline Trauma & $5 / 14$ & $2 / 14$ & $1 / 4$ \\
\hline $\begin{array}{l}\text { Spontaneous } \\
\text { intracranial } \\
\text { hemorrhage }\end{array}$ & $2 / 14$ & $1 / 14$ & $0 / 4$ \\
\hline $\begin{array}{l}\text { Coronary artery } \\
\text { atherosclerosis }\end{array}$ & $2 / 14$ & $8 / 14$ & $0 / 4$ \\
\hline $\begin{array}{l}\text { Sudden death, } \\
\text { epilepsy }\end{array}$ & $0 / 14$ & $1 / 14$ & $0 / 4$ \\
\hline $\begin{array}{l}\text { Acute myocardial } \\
\text { infarction }\end{array}$ & $1 / 14$ & $5 / 14$ & $0 / 4$ \\
\hline Chronic alcoholism & $4 / 14$ & $0 / 14$ & $0 / 4$ \\
\hline Lung weight (g) & $1,242 \pm 504^{\mathrm{c}}$ & $1,599 \pm 524^{\mathrm{c}}$ & $1,557 \pm 433$ \\
\hline Pulmonary edema & $3 / 14^{\mathrm{d}}$ & $10 / 14^{\mathrm{d}}$ & $3 / 4$ \\
\hline Gastric erosions & $9 / 14^{\mathrm{e}}$ & $3 / 14^{\mathrm{e}}$ & $0 / 4$ \\
\hline $\begin{array}{l}\text { Chronic pulmonary } \\
\text { emphysema }\end{array}$ & $3 / 14^{\mathrm{f}}$ & $4 / 14^{\mathrm{f}}$ & $0 / 4^{\mathrm{f}}$ \\
\hline \multirow{2}{*}{$\begin{array}{l}\text { Gas (pulmonary } \\
\text { vessels) }\end{array}$} & No $14 / 14$ & No $14 / 14$ & No $4 / 4$ \\
\hline & Present $0 / 14$ & Present $0 / 14$ & Present $0 / 4$ \\
\hline \multirow[t]{2}{*}{ Gas (soft tissue) } & No $14 / 14$ & No $13 / 14$ & No $4 / 4$ \\
\hline & Present 0/14 & Present 1/14 & Present $0 / 4$ \\
\hline \multirow[t]{3}{*}{ Gas (liver) } & No $13 / 14$ & No $5 / 14$ & No $4 / 4$ \\
\hline & Minimal 1/14 & Minimal 7/14 & Minimal 0/4 \\
\hline & Extensive $0 / 14$ & Extensive $2 / 14$ & Extensive 0/4 \\
\hline \multirow[t]{3}{*}{ Gas (heart) } & No $13 / 14$ & No $7 / 14$ & No $4 / 4$ \\
\hline & Minimal 1/14 & Minimal 5/14 & Minimal 0/4 \\
\hline & Extensive $0 / 14$ & Extensive 2/14 & Extensive $0 / 4$ \\
\hline
\end{tabular}

Group $\mathrm{H}$, both due to absence of resuscitation measures and extensive trauma, also contains considerably less gas

a Age-sex matched groups, differences statistically significant with ${ }^{\mathrm{b}} p<0.001$ (Wilcoxon), with ${ }^{\mathrm{c}} p<0.03$ (Wilcoxon), with ${ }^{\mathrm{d}} p<0.004$ (Barnard's exact test), and with ${ }^{\mathrm{e}} p<0.03$ (Barnard's exact test) and ${ }^{\mathrm{f}}$ no significant difference ( $\mathrm{H}$ vs. $\mathrm{C}$ vs. $\mathrm{CO}$, Chi-Square)

We omitted cases of advanced postmortem decomposition and cases with competitive causes of death such as heat or fire consummation, traumatic injury, or hyperthermia. No age-sex match to the other groups was performed due to the small group size.

Diagnostic considerations

Circumstantial evidence that was interpreted as diagnostic of hypothermia contained a relatively low environmental 
Table 2 Test group details

\begin{tabular}{lll}
\hline & $\begin{array}{l}\text { Fatal } \\
\text { hypothermia }\end{array}$ & $\begin{array}{l}\text { No } \\
\text { hypothermia }\end{array}$ \\
\hline Group size & 7 & 3 \\
Temperature at death scene $\left({ }^{\circ} \mathrm{C}\right)$ & $8.5 \pm 6.1$ & $20.0 \pm 2.0$ \\
Acute intoxication (alcohol, drugs) & $2 / 7$ & $0 / 3$ \\
Coronary artery atherosclerosis & $2 / 7$ & $1 / 3$ \\
Chronic pulmonary & $1 / 7$ & $0 / 3$ \\
emphysema & & \\
Trauma & $1 / 7$ & $0 / 3$ \\
Acute myocardial infarction & $0 / 7$ & $1 / 3$ \\
Brain stem hemorrhage & $0 / 7$ & $1 / 3$ \\
Pneumonia & $0 / 7$ & $1 / 3$ \\
PMCT lung attenuation $(\mathrm{HU})$ & $-822 \pm 43$ & $-564 \pm 121$ \\
GLM predicted probability of & $.94 \pm .04$ & $.21 \pm .34$ \\
membership to group $\mathrm{H}$ & & \\
\hline
\end{tabular}

temperature. In this study, environmental temperature in group $\mathrm{H}$ was $9.8 \pm 8.6^{\circ} \mathrm{C}$ on average, compared to the control group's mean of $22.0 \pm 2.2^{\circ} \mathrm{C}$ (statistically significant, Wilcoxon $p<0.001$ ).

Autopsy findings that suggested fatal hypothermia included livid skin discoloration over the elbows and knees (8/14 in group $H)$, gastric Wischnewski type erosions $(9 / 14$ in group $\mathrm{H})$, hemorrhages within the Psoas muscles $(2 / 14$ in group $\mathrm{H}$ ), and a positive qualitative test for ketone bodies in the urine (9/14 in group H). Pancreatic necrosis was not found in these cases. There was no indication of positional or other mechanical asphyxia in any cases in group $\mathrm{H}$.

Gas due to putrefaction may also contribute to a low lung PMCT interpretation, so we documented the presence of gas as found in postmortem decay [12] or after trauma [13]. PMCT data was evaluated for gas in the heart, pulmonary vessels, liver vessels, and subcutaneous soft tissue on the postmortem CT scans (one examiner, semiquantitative evaluation, see Table 1). Postmortem interval was around 32-36 $\mathrm{h}$ on an average for each of the three groups $\mathrm{H}, \mathrm{C}$, and CO). See Table 1 for an overview.

\section{Test group (T)}

Ten additional cases were selected, using the selection criteria outlined above for group $\mathrm{H}(n=7)$ or $\mathrm{C}(n=3)$. Their pulmonary PMCT attenuation results were used exclusively to test (not to determine) the statistical model.

The seven cases of fatal hypothermia contained gastric erosions (5/7), livid skin discolorations (5/7), a positive qualitative test for ketone bodies in the urine (5/7), and psoas hemorrhages (2/7). For more details of group T, see Table 2.
Lung PMCT attenuation value measurement

Data collection of PMCT attenuation of the lungs was performed as a two reader study. Both readers had considerable experience in PMCT image reading, reporting, and validation of findings at autopsy.

Groups $\mathrm{H}, \mathrm{C}, \mathrm{CO}$, and T contained no deceased with less than two complete lungs. For the left and right lung and for both the suprahilar and infrahilar level, as depicted in Fig. 2, axial images were selected by the first examiner ( $\mathrm{R} 1$, radiologist). In total, four axial lung PMCT images were used to evaluate each case. Serial numbers of axial images that were selected by the first reader were documented. With these serial numbers, the second reader ( 22 , forensic pathologist) could analyze the same.

The first reader defined the slices of the axial images and performed attenuation measurements. The second reader used, for each case, the same slice axial images previously examined. The second reader performed evaluations independently on another computer and at another time. Lung cross sectional areas were segmented manually on standard axial images first (Fig. 2): a marker line was placed about $1 \mathrm{~cm}$ within the perimeter of the pleura. Then, an average CT attenuation value was obtained using standard software; results are given in Hounsfield units (HU). Areas of what appeared to be marked pulmonary hypostasis (internal livor mortis of the lung [14], a typical postmortem finding) were not included in our segmentation. The reason for this is explained below. Determination of PMCT values was performed in a no particular order. Examiners were blinded to case details and the other examiner's findings. For each case, results were averaged before they were compared between observers in order to yield observer agreement. For each case and across both observers, results were averaged to yield one CT attenuation value.

Presence of pulmonary hypostasis

Pulmonary hypostasis is regarded as a phenomenon of gravity dependent accumulation of blood [14]. As a predominantly radiological organ finding similar to livor mortis of the skin, it is usually not examined or described at autopsy. Pulmonary hypostasis is not thought to be related to physiological ante mortem or agonal processes. Therefore, we decided to exclude pulmonary hypostasis from our PMCT attenuation measurements as much as practically possible.

Nevertheless, presence and degree of hypostasis were documented. Presence of hypostasis was judged subjectively. Its visible presence was noted for each case (see Table 3). In addition, difference between CT attenuation was determined by selecting highest and lowest lung attenuation. The highest lung attenuation values were 
Fig. 2 a Lungs were analyzed by selecting four axial imagestwo for each lung with one above and one below the hilus. b Segmentation outlines to define the lung area for CT attenuation averaging were placed manually about $1 \mathrm{~cm}$ within the pleura. $\mathbf{c}$ We omitted areas of apparent postmortem hypostasis (labeled " $\mathrm{H}$ " in the image)
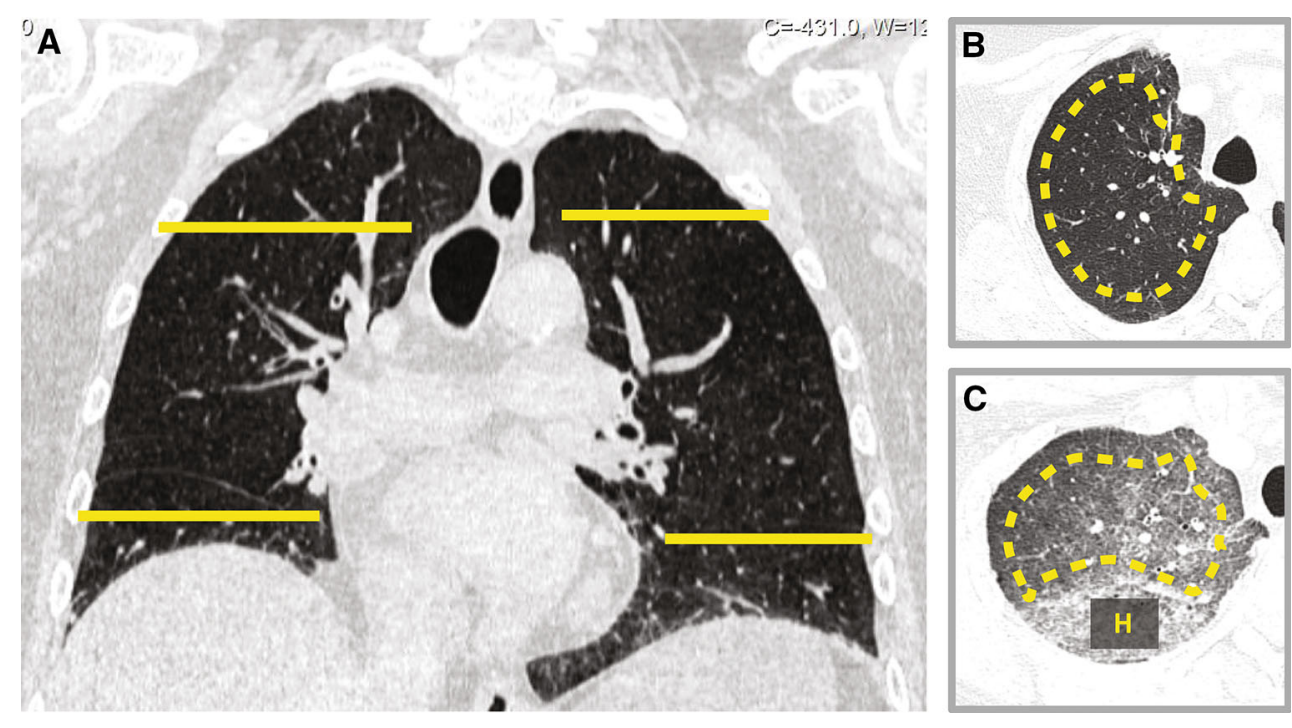

Table 3 Summary of results and interpretation

\begin{tabular}{llll}
\hline & Hypothermia & $\begin{array}{l}\text { CO } \\
\text { poisoning }\end{array}$ & Controls \\
\hline $\begin{array}{l}\text { Pulmonary } \\
\text { hypostasis- } \\
\text { presence }\end{array}$ & $2 / 14(14 \%)^{\mathrm{a}}$ & $4 / 4(100 \%)^{\mathrm{a}}$ & $13 / 14(100 \%)^{\mathrm{a}}$ \\
$\begin{array}{l}\text { Pulmonary } \\
\text { hypostasis- }\end{array}$ & $91 \pm 76^{\mathrm{b}}$ & $496 \pm 78^{\mathrm{b}}$ & $361 \pm 169^{\mathrm{b}}$ \\
$\begin{array}{l}\text { difference in CT } \\
\text { attenuation (HU) }\end{array}$ & & & \\
$\begin{array}{l}\text { PMCT lung } \\
\text { attenuation (HU) }\end{array}$ & $-762 \pm 66$ & $-695 \pm 65$ & $-546 \pm 152$ \\
$\begin{array}{l}\text { Autopsy lung } \\
\text { weights (g) }\end{array}$ & $1,242 \pm 504$ & $1,557 \pm 433$ & $1,599 \pm 524$ \\
$\begin{array}{l}\text { Pulmonary edema } \\
\text { Increased } \\
\text { breathing rate }\end{array}$ & $3 / 14$ & $3 / 4$ & $10 / 14$ \\
$\begin{array}{l}\text { Dose dependent } \\
\text { ODC left shift }\end{array}$ & $++($ Fig. 7) & $++($ Fig. 7) & \\
$\begin{array}{l}\text { Dead space } \\
\text { Cold temperature } \\
\text { induced lung } \\
\text { stiffness }\end{array}$ & $++[8,48]$ & & \\
\hline
\end{tabular}

Hypostasis was not diagnosed in most cases of fatal hypothermia with a significantly lower position dependent lung attenuation difference compared to both CO and C groups (significance a $p<0.0001$ ChiSquare, ${ }^{\mathrm{b}} p<0.0001$ Wilcoxon). While both fatal hypothermia and carbon monoxide poisoning exhibit significantly reduced PMCT lung attenuation, lower lung weights in fatal hypothermia compared to $\mathrm{CO}$ poisoning indicate that mechanisms that differ between both noxious agents need to be considered

mostly dorsally located, the lowest anteriorly. Measurements were performed by capturing the average attenuation of an $8-10 \mathrm{~cm}^{2}$ region using a region-of-interest measurement tool (see Table 3).
Statistical considerations

\section{Reader agreement}

Reader agreement between both readers was determined using the Intra-Class Correlation coefficient (ICC [15, 16] ).

\section{Comparison of PMCT attenuation}

A Shapiro-Wilk test [17] for each of the age-sex matched groups' PMCT attenuations (group $C$, group $H$ ) yielded a statistical significance of $p<0.01$. As a result the normal distribution assumption was rejected. Results for the $\mathrm{CO}$ group conformed to this test. Variances of all three groups (H, C, and $\mathrm{CO})$ were different according to Bartlett's K-squared test of homogeneity of variances [18]. With that, we chose Wilcoxon's nonparametric test [19] over the Student's $t$ test for statistical comparison of PMCT attenuation values (Fig. 3).

Lung PMCT reading, qualitative appreciation and check of plausibility was performed by applying the same attenuation-to-grayscale windowing settings to axial images of all groups (Fig. 4).

\section{Logistic regression}

Our data yields a sparseness indicator of $\psi<0.1$ for the attenuation data of both groups $\mathrm{H}$ and $\mathrm{C}$ (see Eq. 1 quantifying sparseness for vector $v[1, \ldots, n]$ with $\psi=0$ for dense and $\psi=1$ for maximally sparse vectors which uses an $l 1 / l 2$-norm penalization [20] ). However, this indicates that Wald statistics are applicable in this instance [21] as no Hauck-Donner effect should be expected. Subsequently, a General Linear Model (GLM) [22] assuming a binomial 


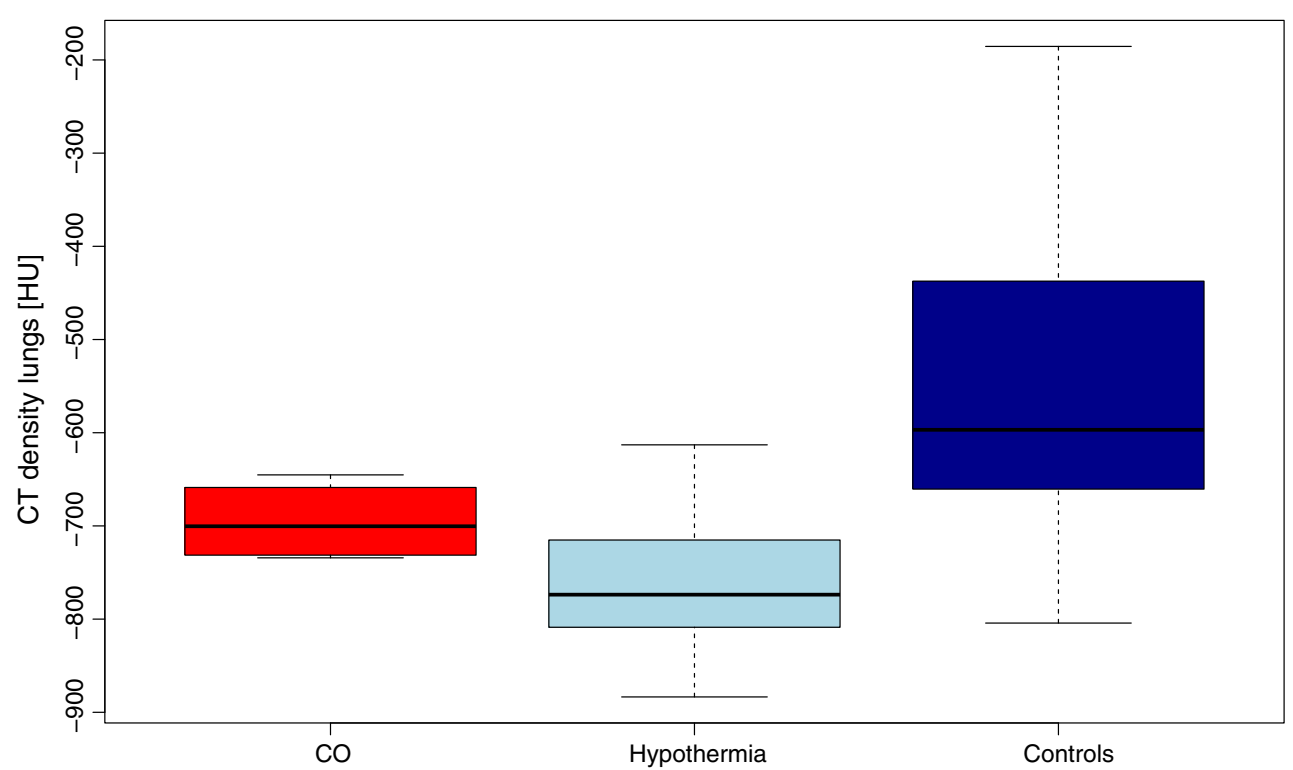

Fig. 3 This box plot shows how CT attenuation (y-axis Hounsfield Units) differ among the three groups examined: the lung CT attenuation in hypothermic death (middle) is statistically significantly lower compared to controls (right). The $\mathrm{CO}$ group (left) also exhibited significantly lower CT attenuation than the controls

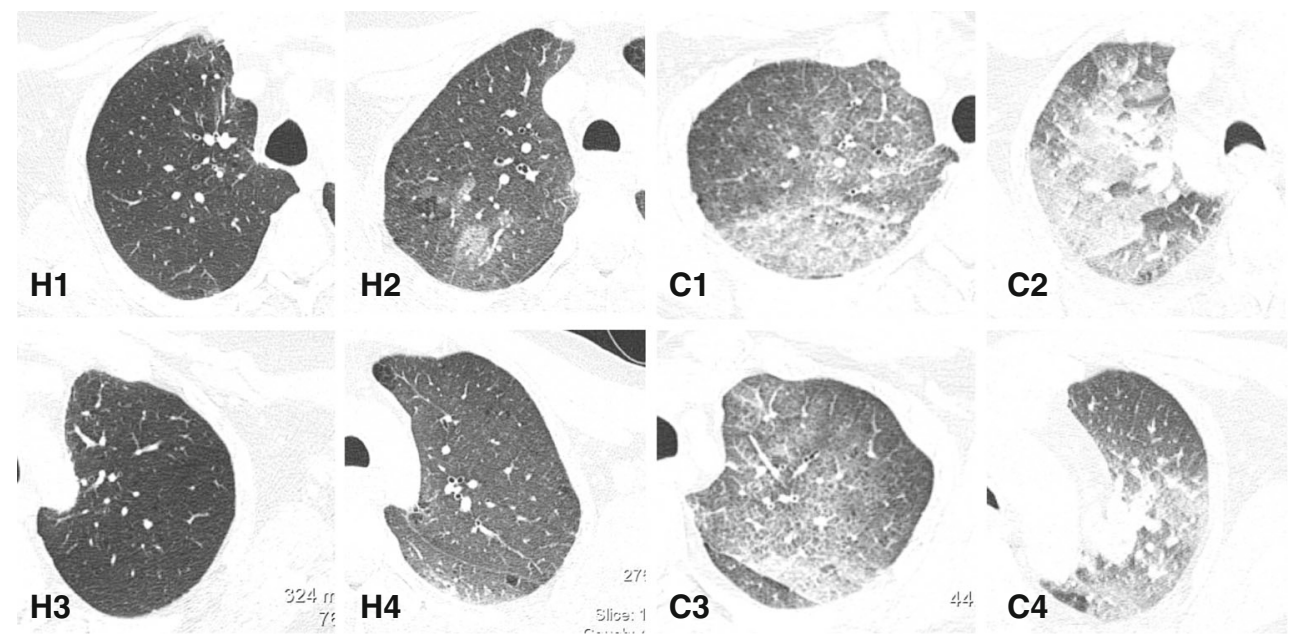

Fig. 4 This image illustrates, on the basis of a number of arbitrarily selected axial images displayed at the exact same attenuation-tograyscale mapping or window, that the lung CT attenuation in

data distribution to determine membership to either $\mathrm{H}$ or $\mathrm{C}$ (equal group sizes) was employed in order to perform and plot [23] a logistic regression (Fig. 5).

Determination of probability for group $\mathrm{T}$ members to be either hypothermic or not hypothermic was achieved by inserting lung PMCT attenuation data of $\mathrm{T}$ into the fitted GLM.

$\psi(v)=\frac{\sqrt{n}-\frac{\|v\|_{1}}{\|v\|_{2}}}{\sqrt{n}-1}=\frac{\sqrt{n}-\frac{\sum_{i=1}^{n} v_{i}}{\sqrt{\sum_{i=1}^{n} v_{i}^{2}}}}{\sqrt{n}-1}$ hypothermic death (image labels $\mathrm{H} 1-\mathrm{H} 4)$ is lower compared to controls (image labels $\mathrm{C} 1-\mathrm{C} 4$ )

Dose-effect correlations-temperature dependent lung attenuation differences within group $H$

We were interested to find out whether there may be a cause-effect relationship. With that assumption and within group $\mathrm{H}$, lower environmental temperatures would have to correlate with even lower PMCT lung attenuation. To investigate a possible dose-response relationship between environmental temperature and PMCT lung attenuation, the hypothermia group $\mathrm{H}$ was split into two groups based on the temperatures at death scenes. This was done along a 
Fig. 5 Logistic regression derived from a General Linear Model shows that given our data (and its inclusion and exclusion criteria), a $90 \%$ probability for fatal hypothermia exists for PMCT lung attenuation of less than $-780 \mathrm{HU}$, whereas based on this data, the probability for missing fatal hypothermia is less than $10 \%$ for PMCT lung attenuation exceeding -590 HU. Test data (triangle pointing down hypothermia, triangle pointing up not hypothermia) was fitted to test the model, details see Table 2

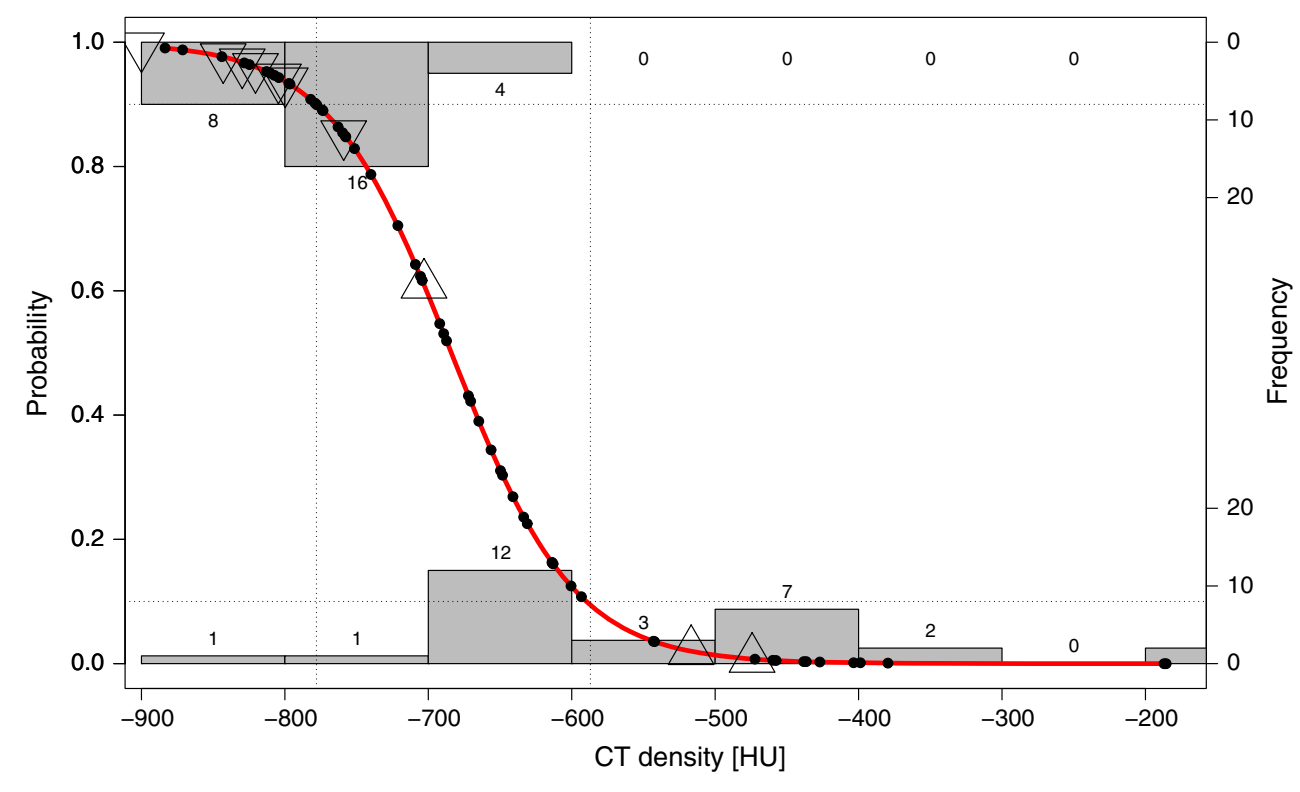

range of different cutoff values $T_{\mathrm{C}} \in{ }^{\circ} \mathrm{C}[1,7]$ for the environmental temperature $T$.

We obtained a number of dichotomous subgroups of $\mathrm{H}$ of different sizes and variances as a function of the continuously varied value of $T_{\mathrm{C}}$ : one hypothermia group is characterized by a lower environmental temperature $H_{\mathrm{L}}$, the other group $H_{\mathrm{H}}$ characterized by higher environmental temperature, with $H=H_{\mathrm{L}} \cup H_{\mathrm{H}}$ and environmental temperatures $T$ conform to $T_{\mathrm{H}_{\mathrm{L}}}<T_{\mathrm{C}}<T_{\mathrm{H}_{\mathrm{H}}}$.

We then compared statistical properties of PMCT attenuation within $H_{\mathrm{L}}$ and $H_{\mathrm{H}}$. With variance unequality and nonnormal data distribution being erratically distributed across the continuity of the varied cutoff values $T_{\mathrm{C}}$ (Shapiro-Wilk's test for normality and Bartlett test for equal variances, see Fig. 6), we used the nonparametric Wilcoxon test to examine statistical significance in PMCT lung attenuation.

And so with varying $T_{\mathrm{C}}$, at a cutoff value of $T_{\mathrm{C}}=2{ }^{\circ} \mathrm{C}$, a split of group $\mathrm{H}$ into $H_{\mathrm{L}}$ and $H_{\mathrm{H}}$ yielded statistical significance for PMCT lung attenuation (Fig. 6).

\section{$\mathrm{CO}-\mathrm{Hb}$ dependent lung attenuation differences within group $\mathrm{CO}$}

In the same manner as splitting group $\mathrm{H}$ based on environmental temperature, group $\mathrm{CO}$ was split based on $\mathrm{CO}$ $\mathrm{Hb}$ concentrations. A best cutoff of $70 \% \mathrm{CO}-\mathrm{Hb}$ resulted, however due to low group member count, only numerical results (but no statistical evaluation) will be reported.

\section{Contingency tables}

For statistical comparison against the other groups, Barnard's exact test was used (CSM [24-26] ).
Mathematical model of the effect of carbon monoxide and hypothermia on the oxygen dissociation curve (ODC)

A carbon monoxide-hemoglobin (CO-Hb) concentration dependent left shift of the ODC results in a pathologically increased hemoglobin's $\mathrm{O}_{2}$-saturation. Increasing $\mathrm{CO}-\mathrm{Hb}$ concentrations yield an increasing disturbance of $\mathrm{O}_{2}$ delivery from capillaries to the tissues [27]. CO poisoning as well as the effects of acute hypothermia [28] both cause a similar left shift of the ODC. To compare their magnitude, we implemented a combined algorithm in $\mathrm{R}$ [22]: one approach models the influence of elevated $\mathrm{CO}-\mathrm{Hb}$ concentration on the ODC shift, and the other one models the increasingly low temperature on the ODC left shift $[29,30]$. We compared our resulting curves with published diagrams from authors covering both temperature [31] and $\mathrm{CO}-\mathrm{Hb}$ [32] effects. That comparison appeared to plausibly validate the combined algorithm.

Software and hardware

Whole body CT scans were obtained on a standard scanning device (Somatom Definition Flash, Siemens, Erlangen, Germany). Scans were obtained at $120 \mathrm{kV}$, reference mAs 400 and $128 \times 0.6 \mathrm{~mm}$ collimation with automated dose modulation (CARE dose4D, Siemens, Erlangen, Germany) [33]. Slice thickness was $2 \mathrm{~mm}$ with an increment of $1 \mathrm{~mm}$. Axial slices were reconstructed with a relatively hard kernel ("B60f", Siemens, Erlangen, Germany). Manual lung cross section segmentation and $\mathrm{CT}$ attenuation measurements were performed using standard radiology image viewing software (Sectra Workstation IDS7, Version 14.3.9.3, Sectra Imtec AB, Linkoeping, Sweden). 

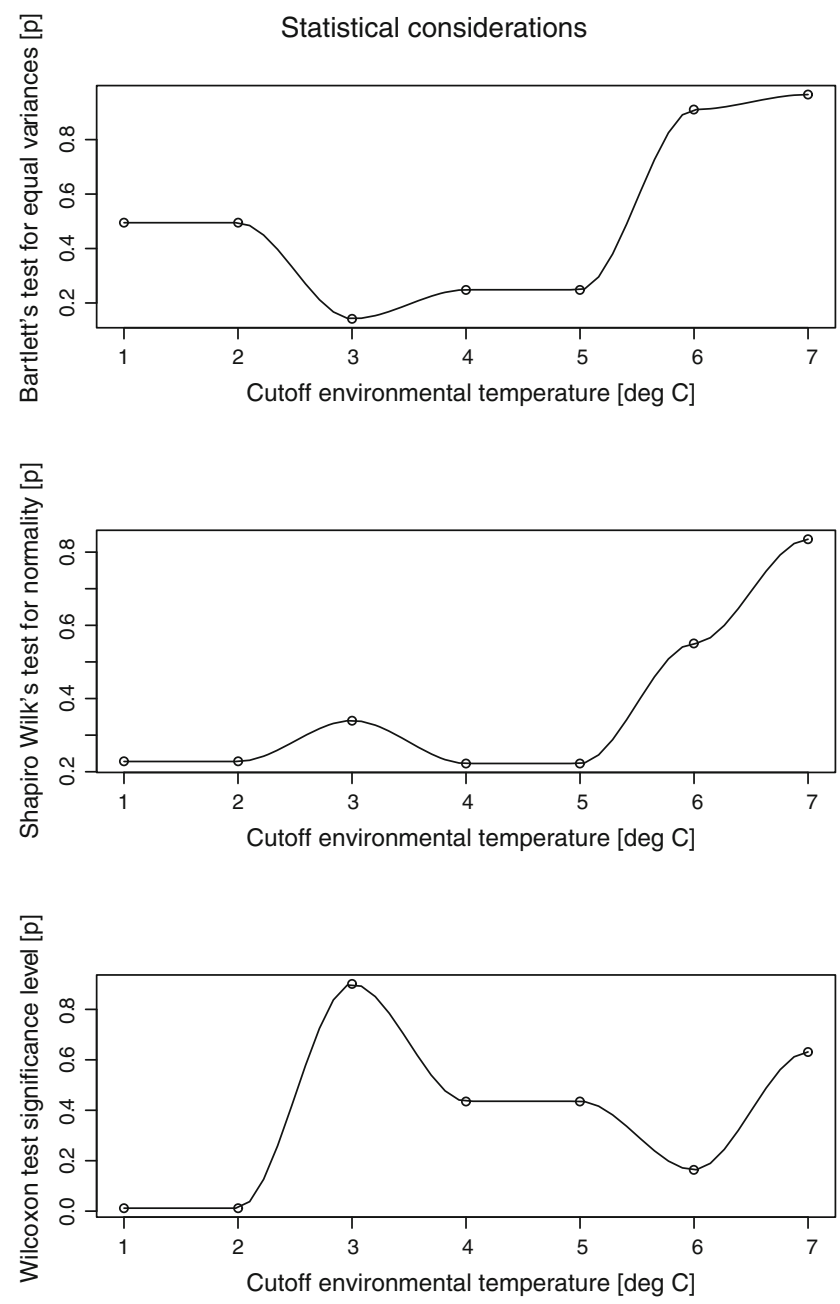

Fig. 6 Pulmonary attenuation within the hypothermia group exhibits a statistically significant split (right diagram) when a cutoff value is placed at $2{ }^{\circ} \mathrm{C}$. Moving the cutoff temperature across $t \in 1,7{ }^{\circ} \mathrm{C}$

Statistical evaluation was performed using $\mathrm{R}$ [R-package [22] Version 2.12.1, including add-ons for intra-class correlation coefficient (IRR [16] Version 0.83) and Barnard's exact test (Exact package [25] Version 1.4)] and JMP (Version 9, SAS Institute, Cary NC).

\section{Results}

PMCT lung attenuation reader agreement

This was done as a two reader study. Reader agreement of pulmonary PMCT attenuation determination was good with an intra-class correlation coefficient of 0.86 .

Pulmonary hypostasis

Pulmonary hypostasis was significantly less frequently present and significantly less pronounced in fatal hypothermia cases compared to controls or $\mathrm{CO}$ poisoning (see Table 3).
CT density in hypothermic deaths

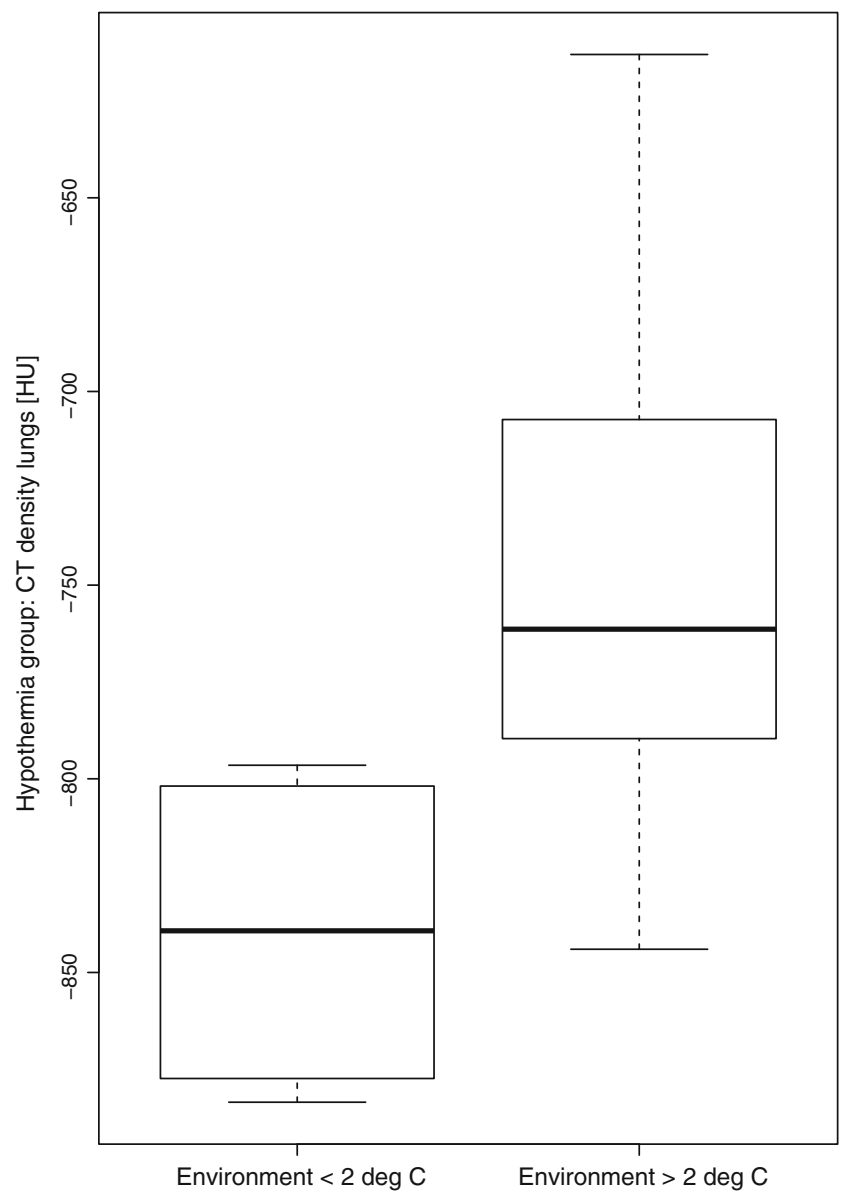

yielded a relatively wide range of variance equality and normality indicators for both subgroups compared within the group $\mathrm{H}$ (diagrams on the left side)

PMCT lung attenuation, lung weights, and pulmonary edema

PMCT lung attenuation was assumed to correlate with both autopsy findings of pulmonary edema and increased lung weights. This is based on the assumption that attenuation of air is higher than the attenuation of water. In order to examine this assumption, PMCT lung attenuation was correlated with the diagnosis of pulmonary edema made at autopsy and with lung weights.

- In cases with the autopsy diagnosis of pulmonary edema (across all three groups $(\mathrm{H}, \mathrm{C}, \mathrm{CO})$, PMCT lung attenuation was significantly $(p<0.03$, Wilcoxon) higher $(-619 \pm 92 \mathrm{HU})$ than in cases with no autopsy finding of pulmonary edema $(-726 \pm 167 \mathrm{HU})$.

- Lung weights were correlated with PMCT lung attenuation across the whole collective (all groups $\mathrm{H}, \mathrm{C}$, and $\mathrm{CO}$ ). Least squares regression established a positive 
correlation, analysis of variance yielded a significance level of $p<0.001$ ( $F$-ratio of 14.2).

As hypothermia appears to entail markedly distended or fluid deprived lungs based on PMCT appearance, we compared lung weights and presence of pulmonary edema. Autopsy derived lung weights $(\mathrm{H}: 1,242 \pm 504 \mathrm{~g}, \mathrm{C}: 1,599 \pm 524 \mathrm{~g}$, Wilcoxon $p<0.03$ ) and pulmonary edema diagnoses (H: $3 / 14$ cases, C: $10 / 14$ cases, Barnard's exact test $p<0.004)$ differed significantly between the hypothermia $(\mathrm{H})$ and control (C) groups. So, hypothermia was less frequently associated with pulmonary edema than the control group, and lung weights in fatal hypothermia were significantly lower. Average lung weights in carbon monoxide poisoning (CO: $1,557 \pm 433 \mathrm{~g}$ ) were higher than the hypothermia group's lung weights, although this was not statistically significant; pulmonary edema was diagnosed significantly more in carbon monoxide poisoning (CO: 3/4 cases) than in the hypothermia group (H: 3/14 cases; $p<0.04$, Barnard's exact test).

PMCT lung attenuation across groups $\mathrm{H}, \mathrm{C}$, and $\mathrm{CO}$

Averaged lung PMCT attenuation was $-762 \pm 66 \mathrm{HU}$ in group $\mathrm{H}$ and was significantly lower than the mean attenuation of $-546 \pm 152 \mathrm{HU}$ in group $\mathrm{C}$ (Wilcoxon $p<0.001)$. PMCT lung attenuation of the $\mathrm{CO}$ group was $-695 \pm 65 \mathrm{HU}$ and also exhibited significantly decreased attenuation compared to controls (Wilcoxon $p<0.03$ ), but was higher than group $\mathrm{H}$, although this difference was not statistically significant (see Fig. 3).

These PMCT attenuation differences between fatal hypothermia and controls are also visibly plausible. This becomes apparent when comparing hypothermic (H1 through H4, Fig. 4) and control (C1 through C4, Fig. 4) lungs in PMCT using the same reconstruction kernel and the same windowing.

\section{Predicting fatal hypothermia}

Fatal hypothermia may be suspected based on the criteria listed above and PMCT findings in a new case. To test that assumption, ten test cases (group $\mathrm{T}$ ) were evaluated using the GLM (i.e., the statistical model) that had been determined based on existing data of groups $\mathrm{H}$ and $\mathrm{C}$.

The logistic regression curve (see Fig. 5) derived from the GLM shows a significant statistical effect of pulmonary PMCT attenuation on group membership $\mathrm{H}$ or $\mathrm{C}$ (given their group definitions), respectively (Wald statistic: $p<0$. 001). The GLM also predicted that given our test data (and its inclusion and exclusion criteria), there would be a $90 \%$ probability for hypothermia with PMCT lung attenuation of less than $-780 \mathrm{HU}$, whereas the probability for overlooking hypothermia is less than $10 \%$ for PMCT lung attenuation greater than $-590 \mathrm{HU}$.

The seven hypothermic cases of test group $\mathrm{T}$ were successfully predicted to be hypothermic based on PMCT lung density alone, with a probability of $94 \%$. The three control cases of group $\mathrm{T}$ yielded an average fatal hypothermia probability of $21 \%$.

To illustrate the test results given by the model, test case CT densities were plotted alongside the fitted model data as triangles (see Fig. 5).

Dose-effect correlations: temperature dependent lung attenuation differences within group $\mathrm{H}$

We investigated whether our data contained correlations indicative of a dose-response effect. Below $2{ }^{\circ} \mathrm{C}$, PMCT yielded lung attenuation of $-840 \pm 44 \mathrm{HU}$, whereas environmental temperatures $>2{ }^{\circ} \mathrm{C}$ correlated with lung attenuation of $-749 \pm 62 \mathrm{HU}$ (Wilcoxon $p<0.02$ ).

So, lower temperatures correlated with lower PMCT lung attenuation more closely than higher temperatures within the victims of fatal hypothermia.

Dose-effect correlations: $\mathrm{CO}-\mathrm{Hb}$ dependent lung attenuation differences within group $\mathrm{CO}$

The group of fatal $\mathrm{CO}$ poisoning contained 4 deaths. At a cutoff of $70 \% \mathrm{CO}-\mathrm{Hb}$, lung attenuation averaged $-672 \pm 108 \mathrm{HU}$ in the lower CO-Hb group (mean $58 \%$ $\mathrm{CO}-\mathrm{Hb}$ ) compared to a slightly lower pulmonary attenuation in the higher $\mathrm{CO}-\mathrm{Hb}$ group (mean $78 \% \mathrm{CO}-\mathrm{Hb}$ ) of $-702 \pm 47 \mathrm{HU}$. So, higher CO-Hb concentrations correlated with lower lung attenuation in PMCT.

Comparison between the effects of hypothermia and carbon monoxide poisoning on the oxygenhemoglobin dissociation curves (ODC)

The direct effect of carbon monoxide (CO) poisoning and hypothermia on the ODC were compared on a one to one basis using a curve plot we obtained from implementing a combined algorithm. With that, a $30 \% \mathrm{CoHb}$ concentration has a comparable effect on the ODC as a temperature of $29^{\circ} \mathrm{C}$, and comparable values to increasing values of $\mathrm{CO}$ poisoning and hypothermia pair $60 \% \mathrm{CoHb} / 22{ }^{\circ} \mathrm{C}$ and $75 \% \mathrm{CoHb} / 9{ }^{\circ} \mathrm{C}$ body core temperature (see Fig. 7).

\section{Discussion}

We found pulmonary attenuation in PMCT to be significantly lower in fatal hypothermia than in age-sex matched 


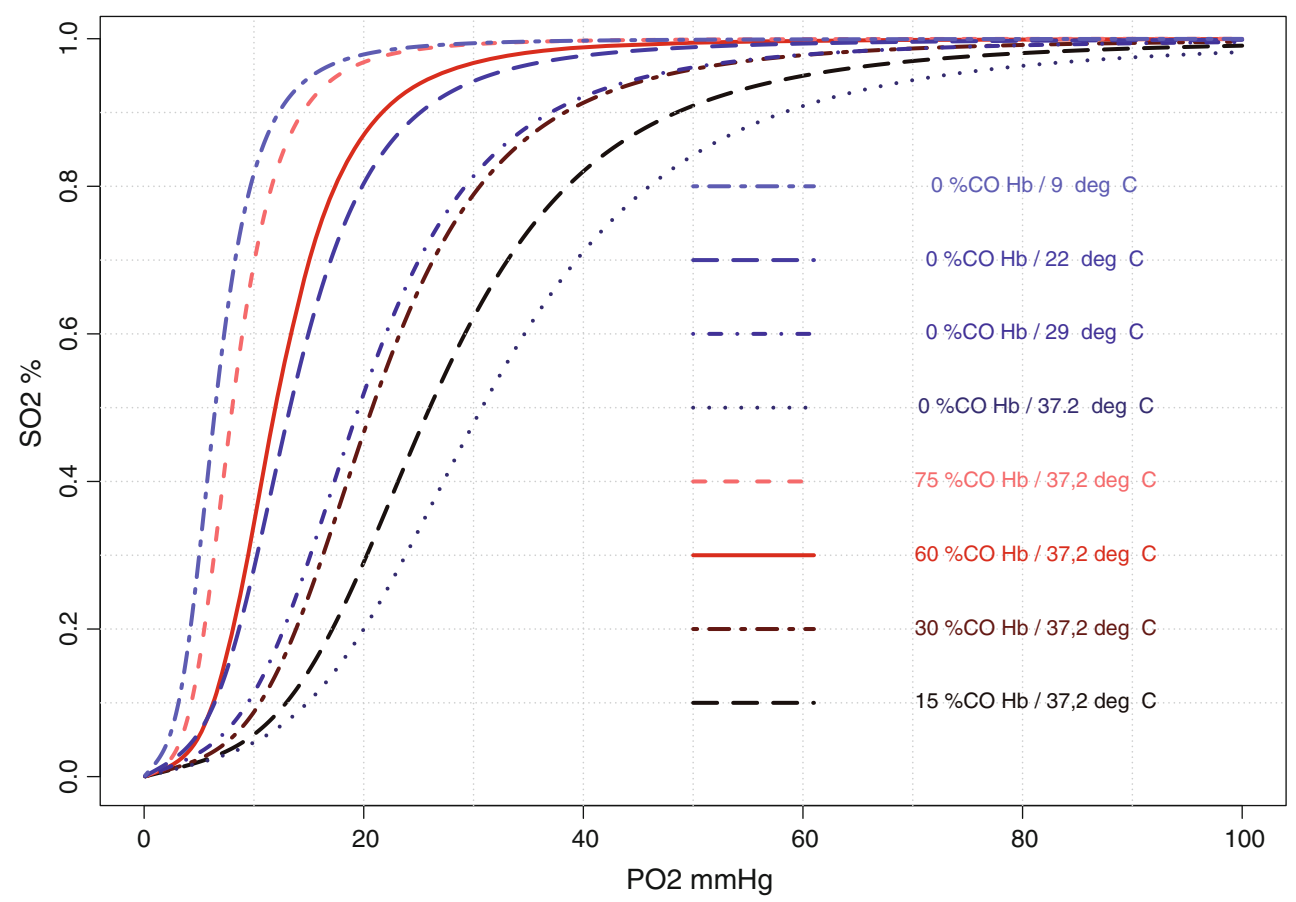

Fig. 7 This plot shows modeled curves for $\mathrm{O}_{2}-\mathrm{Hb}$ dissociation curves (ODC) under influence of both carbon monoxide poisoning and cold temperature

controls. This was not due to postmortem gas accumulation as consequence of trauma, resuscitation, or putrefaction. Rather, the study results suggest that this is an effect of fatal hypothermia.

Lung attenuation of less than $-780 \mathrm{HU}$ appeared to correlate with an observed probability of hypothermic death exceeding $90 \%$ (excluding drowning, gaseous, and mechanical asphyxia such as strangulation and carbon monoxide poisoning). A predictive probability derived from Generalized Linear Model that we determined from study groups $\mathrm{H}$ and $\mathrm{C}$ placed a $94 \%$ probability on seven new test cases of fatal hypothermia compared to a $21 \%$ probability for three non hypothermic deaths in the test group. The question is, what does this observation mean?

Lower than normal attenuation of the lungs in CT is usually caused by over inflation or distension. In the living, emphysema is associated with CT attenuation of less than $-950 \mathrm{HU}[34,35]$. Normal clinical lung attenuation ranges from $-797 \mathrm{HU}$ (10\% vital capacity, expiration) to -877 HU (90\% vital capacity, inspiration) [36]. Conversely, significant pulmonary edema is primarily regarded as accumulation of fluid in airspaces [37]. Presence of pulmonary edema will increase PMCT attenuation of the lungs as shown on PMCT scans; typical CT-appearance of significant edema also is described as ground-glass opacity [38].

In our data, increased PMCT attenuation of lungs correlates with autopsy findings (increased lung weight, pulmonary edema). Conversely, low PMCT attenuation correlates with absence of pulmonary edema and normal autopsy lung weights. The average weight of normal autopsy lungs is reported as 1,246 $\mathrm{g}$ [39]. So, the average lung weight of 1,242 $\pm 504 \mathrm{~g}$ in our hypothermia group did not suggest an increase of fluid content over that found in normal lungs.

Pulmonary edema is generally prevalent in natural death, particularly in conjunction with heart disease [40]. Conversely, pulmonary edema is also seen after intoxication, such as heroin [41-43] or alcohol intoxication. In our control group, lungs weighed, on an average, 1,599 $\pm 524 \mathrm{~g}$ and PMCT lung attenuation was $-546 \pm 152$ HU. Textbooks covering lung findings in fatal hypothermia mention pulmonary edema $[4,5,11]$, but that was not a finding that we found to be typical. However, low PMCT attenuation (average of $-672 \mathrm{HU}$ ) was also observed in four cases of $\mathrm{CO}$ poisoning. In these cases autopsy showed increased lung weights (average of 1,557 $\pm 433 \mathrm{~g}$ ) and pulmonary edema.

So, in our data, fatal hypothermia is associated with distended lungs without signs of pulmonary edema. Carbon monoxide poisoning correlates with distended lungs or acute emphysema, alongside pulmonary edema.

Findings of acute pulmonary emphysema in forensic pathology can be typically found in strangulation [44]. Dry and lightweight lungs are also known from "typical" drowning cases, particularly in fresh water [45]. In drowning, dry lungs may only be seen within a relatively short postmortem interval, whereas bodies retrieved from water after 2 days or more generally tend to exhibit heavier 
lungs [46]. Attempts at forced breathing or increased breathing may occur in strangulation as well as in drowning. To explain increased breathing rates in hypothermia or in carbon monoxide poisoning [47], the left shift of the ODC could be a plausible model. Severe hypothermia and carbon monoxide both have a direct effect on the ODC, and the magnitude of these effects can be compared (see Fig. 7).

However, the degree of pulmonary dryness and distention in fatal hypothermia exceed that in $\mathrm{CO}$ poisoning, so further mechanisms may have to be considered.

Cold temperatures also cause an increased resistance to deflation: a $34 \%$ decrease in dynamical compliance was observed due to cold-dependent mechanical changes of the lungs [48]. At relatively low lung tissue temperatures such as $4{ }^{\circ} \mathrm{C}$, deflation was found to require more pressure than inflation [49]. Muscular energy is reduced in the process of hypothermic agony. Together with rapid cooling rates, the forces required to inflate the lungs might still be provided by the weakened muscles, although the same muscles may not be able to deflate these lungs as well as higher forces are required for that. Thus, this combination may contribute to an inflated appearance of the lung despite a relative reduction in the tidal volumes being breathed.

In addition, cold temperatures can increase dead space in the lung, caused by an absence of the fluid normally contained within pulmonary blood vessels. Hypothermia is known to massively reduce pulmonary perfusion, and even at around $29^{\circ} \mathrm{C}$, over half of the lung capillaries may already be shut down [50]. Conversely, $\mathrm{CO}$ poisoning does not seem to increase dead space by a significant amount [51].

We found a dose-effect relationship in hypothermic deaths (study group $\mathrm{H}$ ), whereas bodies found at environmental temperatures below $2{ }^{\circ} \mathrm{C}$ exhibit a statistically significantly lower PMCT lung attenuation than bodies found at or above $2{ }^{\circ} \mathrm{C}$. Furthermore, slower body cooling rates were found to impact other aspects of metabolism [52] differently when compared to faster cooling rates.

A dose-effect relationship could also be assumed from a difference within the $\mathrm{CO}$ group. Physiological tests and mathematical models document an increase in breathing volume with higher carbon monoxide levels [53].

Given these results and interpretation, low PMCT lung attenuation may indicate fatal hypothermia under the entry criteria for both groups $\mathrm{H}$ and $\mathrm{C}$. Even for the purpose of conservative forensic pathology where X-ray based examinations are restricted [54] or entirely avoided [55], diagnostic criteria that identify fatal hypothermia while examining a cause of death may be of interest, perhaps even more so in the context of a mountain environment, where hypothermia can be hard to diagnose as people may die at low temperatures and relatively high altitudes, and the body is then retrieved for postmortem examination in the midlands.

Limitations of this study

Low PMCT attenuation of the lungs might be a relatively sensitive finding for hypothermia. Also, CO poisoning was found to correlate with below-normal PMCT lung attenuation in our data. So we have to assume that it is not very specific. This study is further limited in that cases of putrefaction, suffocation including drowning (and in particular, drowning in cold water), and strangulation were excluded.

The number of cases in this study is relatively low. Given our specific environment and its climate, fatal hypothermia typically occurs in relatively low temperatures compared to other countries [56]. Our hypothermia group might thus be limited to cases with rather rapid agony, whereas pulmonary edema or pancreatic necroses might be findings pertaining to more extended agony intervals. Some well-known vital reactions to hypothermia may take more time to develop, such as pancreatic necroses, and these were not found at autopsy in any of our cases.

\section{Conclusions}

Pulmonary PMCT attenuation in fatal hypothermia, as well as autopsy lung weights, was found to be significantly lower compared to age-sex matched controls. However, we excluded cases with advanced decomposition from the hypothermia group and we excluded a number of diagnostic groups from the control group.

The underlying mechanisms behind this difference might be found in a significant left shift of the ODC. Other factors that were identified as specific for hypothermia include a temperature dependent increase of deflation over inflation pressures in the hypothermic lung as well as marked increase in dead space. The PMCT finding of strikingly low lung attenuation can be helpful for screening purposes. There, causes of death such as suffocation, including $\mathrm{CO}$ poisoning, suffocation, or strangulation have to be considered, but also, fatal hypothermia should be investigated.

\section{Key points}

1. Fatal hypothermia is associated with low PMCT attenuation of the lungs.

2. The association between hypothermia and low PMCT attenuation of the lungs exhibits a dose-effect relationship. 
3. Low PMCT attenuation of the lungs can be found in other situations such as strangulation so it is not specific for fatal hypothermia.

4. Macroscopic signs of chronic emphysema were equally frequent in this study's hypothermia and control group.

\section{References}

1. Türk EE, Sperhake JP, Pueschel K, Tsokos M. An approach to the evaluation of fatal hypothermia. Forensic Sci Med Pathol. 2005;1(1):31-5.

2. Turk E. Hypothermia. Forensic Sci Med Pathol. 2010;6(2): 106-15.

3. Bright F, Winskog C, Byard RW. Wischnewski spots and hypothermia: sensitive, specific, or serendipitous? Forensic Sci Med Pathol. 2013;9(1):88-90.

4. Hirvonen JK. In: Brinkmann B, Madea B, editors. Handbuch gerichtliche Medizin. New York: Springer; 2004. p. 875.

5. Saukko PJ, Knight B. Knight's forensic pathology. London: Arnold; 2004.

6. Bright F, Winskog C, Walker M, Byard RW. Why are Wischnewski spots not always present in lethal hypothermia? The results of testing a stress-reduced animal model. J Forensic Leg Med. 2013;20(6):785-7.

7. Kanetake J, Kanawaku Y, Mimasaka S, Sakai J, Hashiyada M, Nata M, et al. The relationship of a high level of serum betahydroxybutyrate to cause of death. Leg Med. 2005;7(3):169-74.

8. Rutty GN, Gorincour G, Thali M. Post-mortem cross-sectional imaging: are we running before we can walk? Forensic Sci Med Pathol. 2013;9(3):466.

9. Ruder TD, Flach PM, Thali MJ. Virtual autopsy. Forensic Sci Med Pathol. 2013;9(3):435-6.

10. Hirvonen J, Kortelainen ML, Huttunen P. Pulmonary and serum surfactant phospholipids and serum catecholamines in strangulation: an experimental study on rats. Forensic Sci Int. 1997;90(12):17-24.

11. DiMaio D, DiMaio VJM. Forensic pathology, second edition (practical aspects of criminal \& forensic investigations). Boca Raton: CRC Press; 2001.

12. Levy AD, Harcke HT, Mallak CT. Postmortem imaging: MDCT features of postmortem change and decomposition. Am J Forensic Med Pathol. 2010;31(1):12-7.

13. Farkash U, Scope A, Lynn M, Kugel C, Maor R, Abargel A, et al. Preliminary experience with postmortem computed tomography in military penetrating trauma. J Trauma Acute Care Surg. 2000;48(2):303-9.

14. Christe A, Flach P, Ross S, Spendlove D, Bolliger S, Vock P, et al. Clinical radiology and postmortem imaging (Virtopsy) are not the same: specific and unspecific postmortem signs. Leg Med. 2010;12(5):215-22.

15. Shrout PE, Fleiss JL. Intraclass correlations: uses in assessing rater reliability. Psychol Bull. 1979;86(2):420.

16. Gamer M, Lemon J, Singh IFP. IRR: various coefficients of interrater reliability and agreement. $\mathrm{R}$ package version 0.83 . 2010. http://CRAN.R-project.org/package=irr.

17. Royston J. An extension of Shapiro and Wilk's W test for normality to large samples. Appl Statistics. 1982;31(2):115-24.

18. Bartlett MS. Properties of sufficiency and statistical tests. Proc R Soc London 1937; Series A 160:268-82.
19. Bauer DF. Constructing confidence sets using rank statistics. J Am Stat Assoc. 1972;67(339):687-90.

20. Yin P, Esser E, Xin J. Ratio and difference of $l 1$ and $l 2$ norms and sparse representation with coherent dictionaries. Los Angeles CA: UCLA Department of Mathematics: Computational Applied Mathematic Publications. http://www.math.ucla.edu/applied/cam.

21. Hauck WWJ, Donner A. Wald's Test as applied to hypotheses in logit analysis. J Am Stat Assoc. 1977;72(360):851-3.

22. R Development Core Team. R: a language and environment for statistical computing. Vienna, Austria; 2010. ISBN 3-900051-070 .

23. Stubben CJ, Milligan BG. Estimating and analyzing demographic models using the popbio package in R. J Stat Softw. 2007;22:11.

24. Barnard GA. Significance tests for $2 \times 2$ tables. Biometrika. 1947:34:123-38.

25. Calhoun P. Exact: unconditional exact test; 2013. R package version 1.4. http://CRAN.R-project.org/package=Exact.

26. Mehta CR, Senchaudhuri P. Conditional versus unconditional exact tests for comparing two binomials. 2003. http://www.cytel. com/papers/twobinomials.pdf.

27. Zijlstra WG, Maas AH, Moran RF. Definition, significance and measurement of quantities pertaining to the oxygen carrying properties of human blood. Scand J Clin Lab Invest. 1996;224: $27-45$.

28. Mairburl H, Humpeler E. Diminution of the temperature effect on the oxygen affinity of hemoglobin after prolonged hypothermia. Pflug Arch. 1980;383:209-13.

29. Sharan M, Popel A. Algorithm for computing oxygen dissociation curve with $\mathrm{pH}, \mathrm{PCO} 2$, and $\mathrm{CO}$ in sheep blood. $\mathrm{J}$ Biomed Eng. 1989;11(1):48-52.

30. Kelman GR. Digital computer subroutine for the conversion of oxygen tension into saturation. J Appl Physiol. 1966;21(4): 1375-6.

31. Dash R, Bassingthwaighte J. Erratum to: Blood $\mathrm{HbO} 2$ and $\mathrm{HbCO} 2$ dissociation curves at varied $\mathrm{O} 2, \mathrm{CO} 2, \mathrm{pH}, 2,3-\mathrm{DPG}$ and temperature levels. Ann Biomed Eng. 2010;38(4):1683-701.

32. Zwart A, Kwant G, Oeseburg B, Zijlstra WG. Human wholeblood oxygen affinity: effect of carbon monoxide. J Appl Physiol. 1984;57(1):14-20.

33. Flach PM, Gascho D, Schweitzer W, Ruder TD, Berger N, Ross SG, et al. Imaging in forensic radiology: an illustrated guide for postmortem computed tomography technique and protocols. Forensic Sci Med Pathol. 2014;1-24.

34. Gevenois PA, De Maertelaer V, De Vuyst P, Zanen J, Yernault JC. Comparison of computed density and macroscopic morphometry in pulmonary emphysema. Am J Resp Crit Care. 1995;152(2):653-7.

35. Bankier AA, De Maertelaer V, Keyzer C, Gevenois PA. Pulmonary emphysema: subjective visual grading versus objective quantification with macroscopic morphometry and thin-section CT densitometry. Radiology. 1999;211(3):851-8.

36. Lamers R, Kemerink G, Drent M, Van Engelshoven J. Reproducibility of spirometrically controlled CT lung densitometry in a clinical setting. Eur Respir J. 1998;11(4):942-5.

37. Mills SE. Histology for pathologists. Riverwoods, IL: Wolters Kluwer Health; 2012.

38. Storto ML, Kee ST, Golden JA, Webb WR. Hydrostatic pulmonary edema: high-resolution CT findings. AJR Am J Roentgenol. 1995;165(4):817-20.

39. de la Grandmaison GL, Clairand I, Durigon M. Organ weight in 684 adult autopsies: new tables for a Caucasoid population. Forensic Sci Int. 2001;119(2):149-54.

40. Bourassa MG, Gurné O, Bangdiwala SI, Ghali JK, Young JB, Rousseau M, et al. Natural history and patterns of current practice in heart failure. J Am Coll Cardiol. 1993;22:A14-9. 
41. Duberstein JL, Kaufman DM. A clinical study of an epidemic of heroin intoxication and heroin-induced pulmonary edema. Am J Med. 1971;51(6):704-14.

42. Stein MD. Medical consequences of substance abuse. Psychiat Clin N Am. 1999;22(2):351-70.

43. Winklhofer S, Surer E, Ampanozi G, Ruder T, Stolzmann P, Elliott M, et al. Postmortem whole body computed tomography of opioid (heroin and methadone) fatalities: frequent findings and comparison to autopsy. Eur Radiol. 2014;24(6): 1276-82.

44. Delmonte C, Capelozzi VL. Morphologic determinants of asphyxia in lungs: a semi quantitative study in forensic autopsies. Am J Forensic Med Pathol. 2001;22(2):139-49.

45. Brinkmann B, Madea B. Handbuch Gerichtliche Medizin. Berlin: Springer; 2004.

46. Lunetta P, Modell JH, Sajantila A. What is the incidence and significance of dry-lungs in bodies found in water? Am J Forensic Med Pathol. 2004;25(4):291-301.

47. Penney DG. Acute carbon monoxide poisoning: animal models: a review. Toxicology. 1990;62(2):123-60.

48. Teige K, Koch V, Hartung W. The effect of temperature changes upon the mechanical properties of artificially ventilated normal human lungs. Respiration. 1973;30(2):176-86.
49. Inoue $\mathrm{H}$, Inoue $\mathrm{C}$, Hildebrandt $\mathrm{J}$. Temperature effects on lung mechanics in air- and liquid-filled rabbit lungs. J Appl Physiol. 1982;53(3):567-75.

50. Severinghaus J. Respiration and hypothermia. Ann NY Acad Sci. 1959;80(2):384-94.

51. Santiago TV, Edelman NH. Mechanism of the ventilatory response to carbon monoxide. J Clin Invest. 1976;57(4):977-86.

52. Kozyreva T, Tkachenko EY, Kozaruk V, Latysheva T, Gilinsky M. Effects of slow and rapid cooling on catecholamine concentration in arterial plasma and the skin. Am J Physiol-Reg I. 1999;276(6):R1668-72.

53. Stuhmiller JH, Stuhmiller LM. A mathematical model of ventilation response to inhaled carbon monoxide. J Appl Physiol. 2005;98(6):2033-44.

54. Bolliger SA, Ketterer T. Wo liegen die Vorteile der Bildgebung in der rechtsmedizinischen Praxis? Pipette Swiss Lab Med. 2012;11(4):14-5.

55. Hausmann R. Der plötzliche Tod im Kindesalter. Ther Umsch. 2008;65(7):407-11.

56. Aitken LM, Hendrikz JK, Dulhunty JM, Rudd MJ. Hypothermia and associated outcomes in seriously injured trauma patients in a predominantly sub-tropical climate. Resuscitation. 2009;80(2): 217-23. 